\title{
Technologies and practices of mechanized backfill mining for water protection with aeolian sand paste-like
}

\author{
Pengliang Liu China Coal Research Institute / Tiandi Science and Technology Co, Ltd, China
}

\section{Abstract}

Given the serious problem of Salawusu Formation Aquifer damage caused by caving mining in Yuyang Coal Mine, the technique of mechanized mining backfill with paste-like slurry using Aeolian sand was invented. The backfill used Aeolian sand as aggregate and alkali-activated fly ash as the cementing agent. The water-sand ratio was 1:1.3, with a mass concentration of $72 \%$, and the initial fluidity of the filling slurry reached $210 \mathrm{~mm}$. This paper proposes a calculation method for the local resistance loss of slurry transportation with pipeline, and the field gravity transport test results showed that the resistance loss of unit length elbow was 4.26 times as great as that along the path. Therefore, the pipeline diameter for the 14.9 lines of self-flowing was determined, and the pipeline flow design precision was improved by over $10 \%$. The filling capacity reached $360 \mathrm{~m}^{3} / \mathrm{h}$ and the running energy consumption was low after adopting the filling station model of double pulping system and underground equipment pool. The paper also puts forward the method of whole filling space sealing with a cloth consumption being only $40 \%$ of that using the bag filling. Industrial test showed that the technique also protected water resources, based on the fact the filling rate was $98.5 \%$ in goaf, strata behavior slightly appeared, roof water leaching was less than $2 \mathrm{~m}^{3} / d$, and the surface subsidence value was $38 \mathrm{~mm}$. Meanwhile, great breakthroughs have been achieved in lowering and improving production efficiency compared with similar technology.

\section{Introduction}

Mining methods such as strip mining and limited mining minimize the damage of overlying strata by reducing resource recovery so as to protect water bodies (Fan et al., 2015; Xia et al., 2016). Comparatively, the environmental-friendly backfill mining is ideal to control rock movement by filling solid or cemented material in goaf with no loss of coal resources. In recent years, backfill mining with waste gangue and fly ash as the main backfill materials has been rapidly developing and is applied in mining under buildings and around water areas in the mining area in Eastern and Central China (Miao, 2012; Hu, 2012; Feng et al., 2010; Liu et al., 2014; Sun et al., 2015; Qiu et al., 2016; Zhang et al., 2014), with remarkable economic and environmental benefits having been achieved. Given the urgent need for water protection in mining and extensive occurrence of Aeolian sand in Northwest coal mining area, it is imperative to use Aeolian sand as the aggregate in backfill mining. Fan (2003) proposed the use of Aeolian sand for water conservation. Yan et al. (2008) presented an innovative gateway and pillar top coal caving mining method for water protection. Cui and others tested the basic properties of Aeolian sand and the performance of cemented backfill materials with Aeolian sand as the aggregate (Cui et al., 2009; Sun, 2014; Sun et al., 2016; Wang, 2016). Previous studies have promoted the development of Aeolian sand backfill mining, but the systems of slurry preparation and backfill mining based on Aeolian sand have not been fully developed, and the engineering practices are also absent. In addition, the efficiency of backfill mining is related to its application value, making it important to improve the production capacity and reduce the cost of materials, processes and systems. This paper developed paste- 
like backfill materials with excellent liquidity using Aeolian sand, and established 14.9 times line of self-

flowing transportation system. It used the double pulping systems in the filling station mode to reduce energy consumption and proposed a new whole filling space sealing and invented Aeolian sand paste-like backfill mining with higher efficiency and lower cost. In the research that lasted for three years, mining test was carried out in 2307 fully-mechanized backfill mining work face in Yuyang Coal Mine and successfully protected the overlying aquifer, thus providing a reference for its application in mining area in Northwestern China.

The 2307 fully-mechanized backfill mining test face was located in the southwest of the mine, and the 2301 continuously stretches to the north, with the unmined area to the south, boundary pillar to the west, and south main return way to the east. The strike length and width of the working face was 1149 and $150 \mathrm{~m}$ (not including that of the two lanes), respectively, with an average mining thickness of $3.5 \mathrm{~m}$ and a dip of $0.28^{\circ}$. The floor level, ground level, and buried depth was +966 +971 m, +1160 +1169 m, and 190 198 m, respectively. The surface field scattered the houses of Xiaojiahuochang. For monitoring surface movement and deformation, a strike survey line with the total length of $690 \mathrm{~m}$ was arranged above the cut-hole (see Figure 2), including three control points ( $A 1, A 2$, and $A 3$, with a distance of $50 \mathrm{~m}$ between every two points), 29 observation points (1\# 29\#, with a distance of $20 \mathrm{~m}$ between every two points). A monthly observation was done from the mining start.

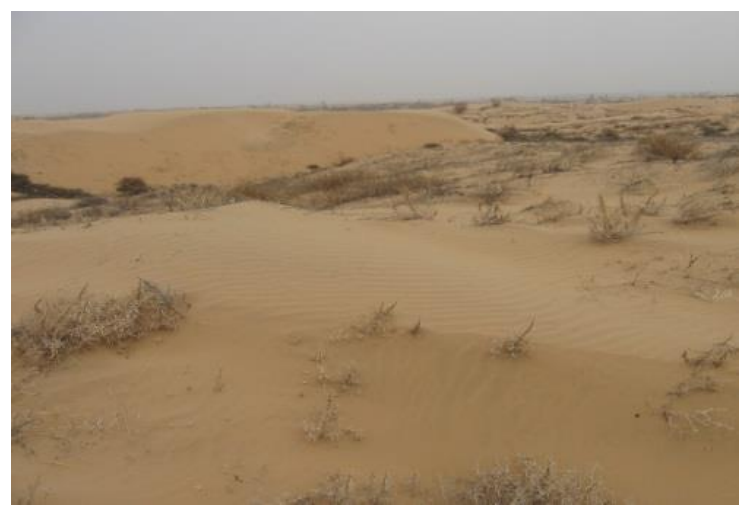

Figure 1 Aeolian sand landscape in Yuyang Coal Mine

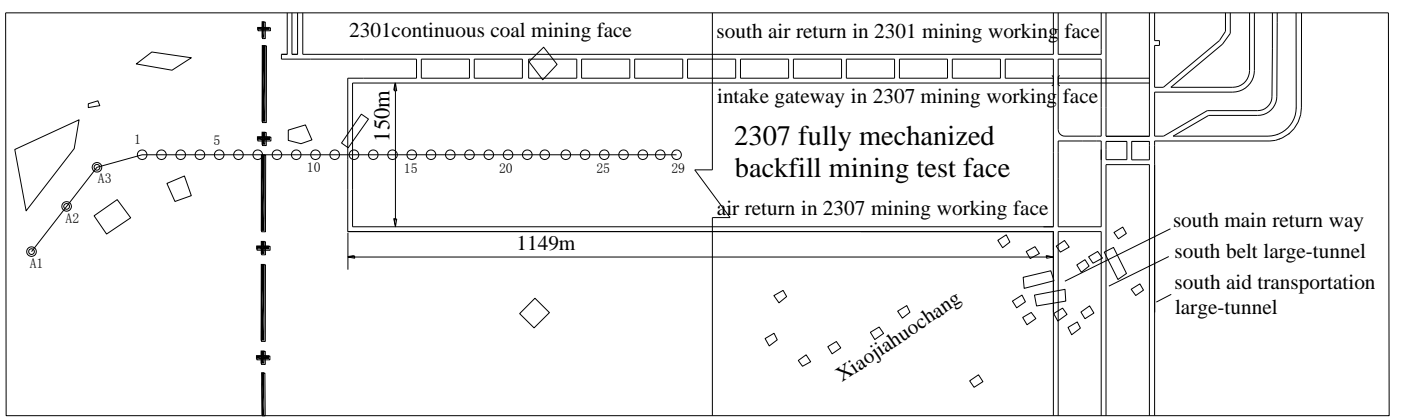

Figure 2 The 2307 fully mechanized mining filling face and surface movement deformation observation point

\section{Characteristics of Aeolian sand paste-like backfill materials}

\subsection{The composition of backfill materials}

\subsubsection{Aeolian sand}

Black dust, weeds and loess tuberculosis were blown and transported by wind and accumulated in the area no deeper than $50 \mathrm{~cm}$. In comparison, few impurities, pure yellow and colorless Aeolian sand particles are found in the area deeper than $50 \mathrm{~cm}$ in Yuyang Coal Mine surface. A total of 28 sand samples were collected, 
with the main minerals being quartz, feldspar, and mica observed through microscope (Figure 3). X-ray diffraction analysis showed that $\mathrm{SiO}_{2}, \mathrm{Al}_{2} \mathrm{O}_{3}, \mathrm{CaO}, \mathrm{Fe}_{2} \mathrm{O}_{3}$ and $\mathrm{MgO}$ were included, and the main components of $\mathrm{SiO}_{2}$ and $\mathrm{Al}_{2} \mathrm{O}_{3}$ accounted for 65.75 and $12.83 \%$, respectively. Screening test showed that the Aeolian sand was a super fine sand, their size concentrating within $0.075 \sim 0.6 \mathrm{~mm}$, with the average and maximum size being 0.249 and $1.0 \mathrm{~mm}$, respectively. The uniformity coefficient $\mathrm{Cu}=2.49$, and the coefficient of curvature $\mathrm{Cc}=1.03$. The bulk density was $1.503 \sim 1.543 \mathrm{~g} / \mathrm{cm}^{3}$, and the porosity was $40.2 \sim 42.5 \%$. The apparent density was $2.571 \sim 2.599 \mathrm{~g} / \mathrm{cm}^{3}$ (Sun, 2014; Sun et al., 2016).

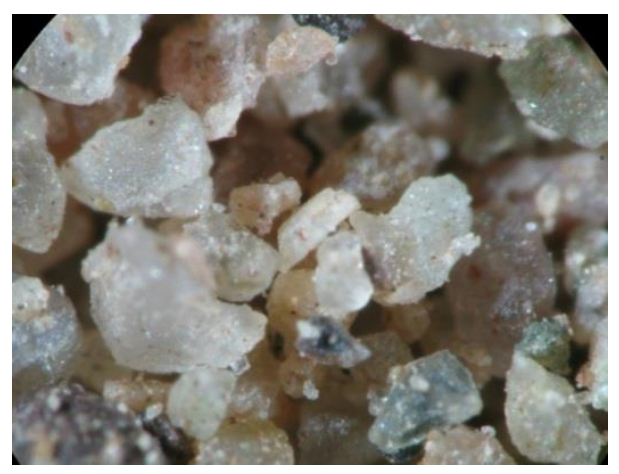

Figure 3 Electron microscope of Aeolian sand $(\times 100)$

\subsubsection{Cementing material}

Alkali activated cementing material is a new non-metallic cementitious material developed using materials with volcano properties or potential hydraulicity (such as slag and fly ash). The reactivity to generate hydraulic cementing performance is generated by adding alkaline agent. The material fully uses industrial wastes and is of low cost. Meanwhile, its strength and resistance to acidity, alkali, and carbonation are superior to that of Portland cement (Jiang, 2012). Fly ash was chosen as the main material, with lime, gypsum, and cement as the alkaline agents in this cementing material for backfilling.

\subsubsection{Water}

Mine water can be used in the preparation of backfill materials.

\subsection{Proportioning experiment of backfill materials}

The main performance indexes of cement backfill materials include the rheological parameters (fluidity, viscosity, and yield stress) of backfill slurry, final setting time, bleeding rate, and strength of backfill body. Two factors and four level orthogonal experiments were adopted to test the performance of backfill with different water-sand ratios (1:0.7, 1:1, 1:1.3, and 1:0.4) and mass concentrations (66, 69, 72 , and 75\%). The experimental results are shown in Table 1.The measurement of slurry flow is shown in Figure 4.

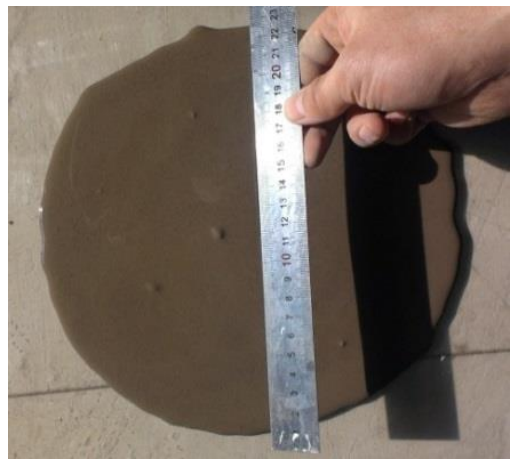

Figure 4 The fluidity test of Aeolian sand paste-like

Compared with the current backfill materials used (Lu, 2006; Fu et al., 2003; Zhang et al., 2013), paste-like 
Aeolian sand is characterized by excellent liquidity and high strength. In order to further improve the performance of and fully utilize Aeolian sand, the water-sand ratio of $1: 1.3$ and mass concentration of $72 \%$ was chosen finally.

Table 1 Experimental results of different ratio backfill

\begin{tabular}{|c|c|c|c|c|c|c|c|c|c|c|c|}
\hline \multirow[t]{2}{*}{ Number } & \multirow{2}{*}{$\begin{array}{c}\text { Concentration } \\
\text { (\%) }\end{array}$} & \multirow{2}{*}{$\begin{array}{l}\text { Water } \\
\text { sand } \\
\text { ratio }\end{array}$} & \multirow{2}{*}{$\begin{array}{c}\text { Viscosity } \\
\text { (Pa.s) }\end{array}$} & \multirow{2}{*}{$\begin{array}{c}\text { Yield } \\
\text { stress } \\
(\mathrm{Pa})\end{array}$} & \multirow{2}{*}{$\begin{array}{l}\text { Initial } \\
\text { fluidity } \\
(\mathrm{mm})\end{array}$} & \multirow{2}{*}{$\begin{array}{l}\text { Final } \\
\text { setting } \\
\text { time } \\
\text { (h) }\end{array}$} & \multirow[t]{2}{*}{$\begin{array}{c}\text { Bleeding } \\
\text { rate (\%) }\end{array}$} & \multicolumn{4}{|c|}{$\begin{array}{c}\text { Strength of different age } \\
(\mathrm{MPa})\end{array}$} \\
\hline & & & & & & & & $12 \mathrm{~h}$ & $3 \mathrm{~d}$ & $7 d$ & $28 \mathrm{~d}$ \\
\hline 1 & 66 & 1:0.4 & 0.034 & 0.83 & 280 & 7.5 & 2.1 & 0.18 & 2.07 & 2.86 & 4.28 \\
\hline 2 & 69 & $1: 0.7$ & 0.096 & 2.31 & 266 & 6.2 & 0.9 & 0.21 & 2.15 & 3.30 & 4.92 \\
\hline 3 & 72 & 1:1 & 0.256 & 4.85 & 206 & 6.2 & 1.0 & 0.19 & 2.20 & 3.31 & 4.77 \\
\hline 4 & 75 & $1: 1.3$ & 0.848 & 8.78 & 190 & 5.8 & 1.3 & 0.25 & 2.56 & 3.44 & 5.02 \\
\hline 5 & 66 & $1: 0.7$ & 0.102 & 2.29 & 270 & 6.6 & 2.7 & 0.18 & 2.09 & 3.20 & 4.71 \\
\hline 6 & 69 & 1:1 & 0.110 & 2.43 & 247 & 6.5 & 1.2 & 0.19 & 1.98 & 3.12 & 4.67 \\
\hline 7 & 72 & 1:1.3 & 0.261 & 5.04 & 210 & 6.0 & 1.2 & 0.20 & 2.11 & 3.23 & 4.80 \\
\hline 8 & 75 & $1: 0.4$ & 0.229 & 4.18 & 211 & 6.0 & 0.2 & 0.28 & 2.52 & 3.68 & 5.06 \\
\hline 9 & 66 & 1:1 & 0.087 & 1.76 & 269 & 6.9 & 3.1 & 0.12 & 1.52 & 2.63 & 4.05 \\
\hline 10 & 69 & 1:1.3 & 0.124 & 2.61 & 240 & 6.3 & 1.5 & 0.18 & 1.92 & 3.02 & 4.55 \\
\hline 11 & 72 & $1: 0.4$ & 0.217 & 4.02 & 213 & 6.2 & 0.3 & 0.22 & 2.23 & 3.26 & 4.88 \\
\hline 12 & 75 & $1: 0.7$ & 0.243 & 4.52 & 208 & 6.0 & 0.5 & 0.24 & 2.41 & 3.53 & 4.98 \\
\hline 13 & 66 & 1:1.3 & 0.102 & 1.99 & 260 & 6.5 & 3.5 & 0.15 & 1.76 & 2.89 & 4.23 \\
\hline 14 & 69 & 1:0.4 & 0.201 & 3.87 & 220 & 6.4 & 0.6 & 0.20 & 2.17 & 3.01 & 4.54 \\
\hline 15 & 72 & 1:0.7 & 0.238 & 4.37 & 214 & 6.1 & 0.6 & 0.17 & 2.26 & 3.34 & 4.87 \\
\hline 16 & 75 & $1: 1$ & 0.264 & 4.96 & 193 & 6.1 & 0.8 & 0.21 & 2.32 & 3.48 & 4.90 \\
\hline
\end{tabular}

3 The filling station mode of double pulping systems with low energy

\section{consumption}

The preparation system of backfill using paste-like Aeolian sand consists of initial slurry tanks, auxiliary tanks (storing activator), cement tanks, slurry tanks, Aeolian sand sieving and conveying systems and fly ash bases. The pulping process first injected water into the initial slurry tanks, and after stirring motor was started, it injected fly ash to make initial slurry. The eccentric horizontal synchronous sieve (with a screen size of 25 $\mathrm{mm}$ ) was adopted to clean Aeolian sand, and sand products were conveyed and metered through belt conveyor and electronic belt, respectively; the initial slurry, ingredients (e.g. alkali-activated fly ash), cement and Aeolian sand were mixed in proportion and then transported to the slurry tank where they are mixed uniformly. Automatic control was adopted in the entire process of material feeding, liquid level monitoring and so on.

The pulping capacity of filling station is only $60 \sim 150 \mathrm{~m}^{3} / \mathrm{h}$, with the single system restricting the production capacity. Therefore, two sets of pulping system with a pulping capacity of $180 \mathrm{~m}^{3} / \mathrm{h}$ were adopted and centralized to simultaneously operate in the filling station (see Figure 5(a) for the plan sketch). The maximum filling capacity can reach $360 \mathrm{~m}^{3} / \mathrm{h}$ with the prepared slurry transporting to the work face by two pipelines. The main equipment of dual pulping systems is shown in Table 5.

The high storage tank led to high energy consumption and operation cost in water, ash, and material supplying process. Hence, the filling station was designed into an underground equipment pool, as shown in 
Figure 5(b). In the station, the initial slurry, auxiliary, and cement tanks were placed $10 \mathrm{~m}$ under the ground. With the top of tanks being parallel to the ground, the ash can be fed horizontally. The storing, screening and conveying systems of Aeolian sand were arranged from ground to $10 \mathrm{~m}$ below so that they can be naturally transported down for the screening; slurry tanks were placed $15 \mathrm{~m}$ under the ground, with its top parallel to the bottom of the above equipment, and the initial slurry and all materials can be transported horizontally, which greatly reduces energy consumption. The photographs of pulping equipment in the field pool are shown in Figure 5(b).

Table 2 Main equipment of double pulping systems

\begin{tabular}{ccccc}
\hline Number & Equipment name & $\begin{array}{c}\text { Specification and } \\
\text { type }\end{array}$ & Quantity & Remarks \\
\hline 1 & initial slurry tank & $100 \mathrm{~m}^{3}$ & 8 & $\begin{array}{c}\text { 4 per system } \\
\text { auxiliary tank }\end{array}$ \\
2 & $80 \mathrm{~m}^{3}$ & 2 & $\begin{array}{c}\text { 1 per system, filled with lime and } \\
\text { gypsum mixture }\end{array}$ \\
3 & $\begin{array}{c}\text { cement tank } \\
\text { slurry tank }\end{array}$ & 803 & 2 & 1 per system \\
4 & screening and conveying systems & $16 \mathrm{~m}^{3}$ & 2 & 1 per system \\
5 & of Aeolian sand & $200 \mathrm{t} / \mathrm{h}$ & 2 & 1 per system \\
\hline
\end{tabular}

\section{$4 \quad$ A new whole backfill space sealing}

The short "mining-filling-backfill solidification" cycle is adopted in cement backfill mining face. After mining in each cycle, rapid and effective construction of backfill space is crucial for the improvement of filling efficiency. The suspending bags with strong fiber cloth in the rear of the supports and filling bags with slurry were currently used (Feng, 2010), which solved the problem of construction within confined space in complicated geological environment, but there are still such problems as relatively dangerous working environment, a large number of bags used, and a large amount of material consumption. 


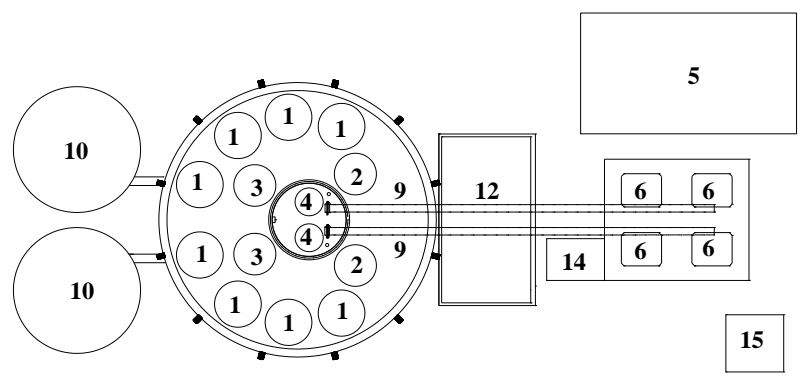

(a)

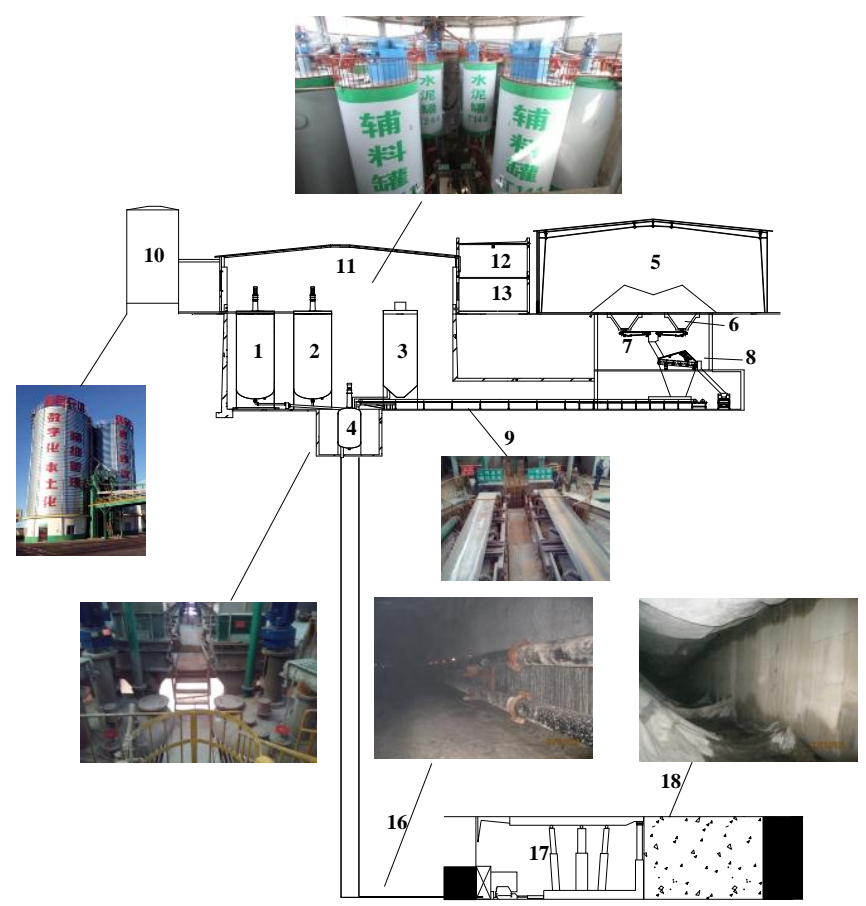

(b)

1 - initial slurry tanks; 2 - auxiliary tanks; 3 - cement tanks; 4 - slurry tanks; 5 - Aeolian sand pile; 6 - sand inlets; 7 - constant feeder; 8 - vibration sieve; 9 - finished sand belt; 10 - fly ash bases; 11 - equipment pool underground; 12 - offices; 13 - control rooms; 14 - lifting room; 15 - material discharging port; 16 - slurry pipelines(2); 17 - the supports in backfill mining face; 18 - filling body

\section{Figure 5 The layout and scene of filling station in Yuyang Coal Mine; (a) lan sketch; (b) section sketch with photographs}

A new whole backfill space sealing was put forward, laying the entire area after mining with fiber cloth along the roof and on the floor in the rear of the supports. The upper and lower layers of fiber cloth were squeezed by the mechanical force in the supports, so that a closed space is formed in the rear goaf, as shown in Figure 6. The related structure and function of supports are as follows: the operating room is arranged at the rear part, and the fixed and lifting baffle plates are set at the gob side. Fixed baffle and hydraulic support base are integrated, and the lifting baffle with flexible pad arranged on the top is connected with the fixed baffle slip. The fiber cloth is laid along the roof, the coal wall of the cutting hole and the floor in the rear of the supports from the start of mining. The two sides of the fiber cloth are drawn to the operation room under support, and the lifting baffle plate is then raised, while the top and the bottom cloth were squeezed between the lifting baffle plate and support beam. The fiber cloth should be sutured or sealed at both ends of the working face so that a closed backfill space is formed. Paste-like slurry using Aeolian sand was transported through pipeline to fill the rear space. The fiber cloth in the operating room is connected to prepare for the next cycle during backfill solidification. When the backfill solidification meets the strength requirements, the lifting 
baffle is lowered, supports are moved forward, and the fiber cloth is removed from the filling body. Then the next cycle of mining backfill in in operation. The backfill system is shown in Figure 5(b) - 18.

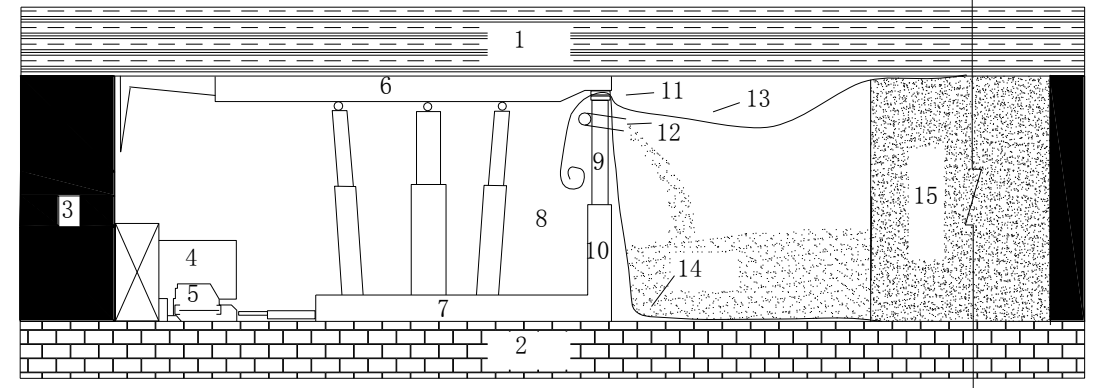

1 - roof; 2 - floor; 3 - coal wall in the front; 4 - coal mining machine; 5 - scraper conveyor; 6 - support beam; 7 - support base; 8 - the operating room; 9 - lifting baffle plate; 10 - fixed baffle plate; 11 - flexible pad; 12 outlet of filling pipe; 13 - cloth on the roof; 14 - cloth on the floor; 15 - filling body

Figure 6 Whole filling space sealing in working face

The advantages of whole backfill space sealing include: workers can simply operate in the operating room of supports, without having to enter the goaf and could have their safety guaranteed; the sealing of fiber cloth by mechanical forces reduces labor intensity and improves working efficiency. Furthermore, cloth consumption is greatly reduced. Take the $\mathbf{2 3 0 7}$ working face as an example, if bag filling is adopted with a bag size of $10 \mathrm{~m}(\mathrm{~L}) * 3 \mathrm{~m}(\mathrm{~W}) * 3.5 \mathrm{~m}(\mathrm{H}), 6000$ bags are needed in the entire goaf, and the total amount of cloth is approximately $900,000 \mathrm{~m}^{2}$, but using whole backfill space sealing, the cloth consumed is only appximately $360,000 \mathrm{~m}^{2}$

\section{$5 \quad$ Practice of mechanized coal mining with Aeolian sand paste-like}

\subsection{Operation of mining and filling system}

In October 2012, the mechanized mining backfill system with paste-like slurry using Aeolian sand was built in Yuyang Coal Mine, and industrial experiment was carried out in late November in the 2307 working face. By mid-December 2013, the working face was advanced for $310 \mathrm{~m}$, had mined 213,000 tons of coal, filled $170,000 \mathrm{~m}^{3}$ of slurry and consumed 85,000 tons of mine water, 83,000 tons of cement, 12,000 tons of activator and 111,000 tons of Aeolian sand. However, the backfill mining was terminated after the mine was closed.

In the early industrial test, insufficient system running degree and unskilled workers led to problems in field implementation and caused low production efficiency, which was then gradually improved later.

\subsection{Water preservation effect}

A total of 72 mining filling cycles were carried out in the working face. The conditions of the connection of filling body with its top along the working face in each cycle were observed and recorded. Statistical results showed that the average filling rate in goaf was as high as $98.5 \%$ because of low bleeding rate and strict site management.

A total of 88 fully mechanized mining filling supports were placed in the working face, and one pressure measuring station was installed every ten supports. The measured data from December 11th, 2012 to December 11th, 2013 showed that, the pressure was relatively greater in the middle of working face and gradually decreased in the face end, and the roof pressure was overall smaller, which changed moderately with the advancing of working face, and no obvious periodic pressure appeared on the roof. The resistancetime (P-T) curve of $47 \#$ support in the middle of the working face is shown in Figure 7. 


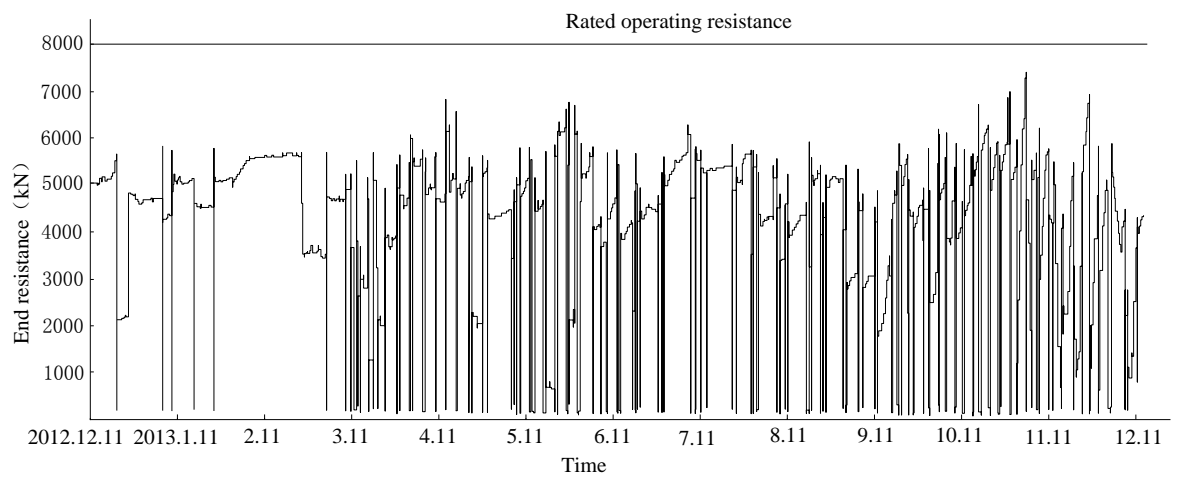

Figure 7 P-T curve of 47 \# hydraulic support in the middle of mining face

The final surface subsidence curve is shown in Figure 8. The maximum subsidence is $38 \mathrm{~mm}$, located at the 22\# measuring point, with the distance from the cutting hole being $196 \mathrm{~m}$. The buildings on the surface were not affected.

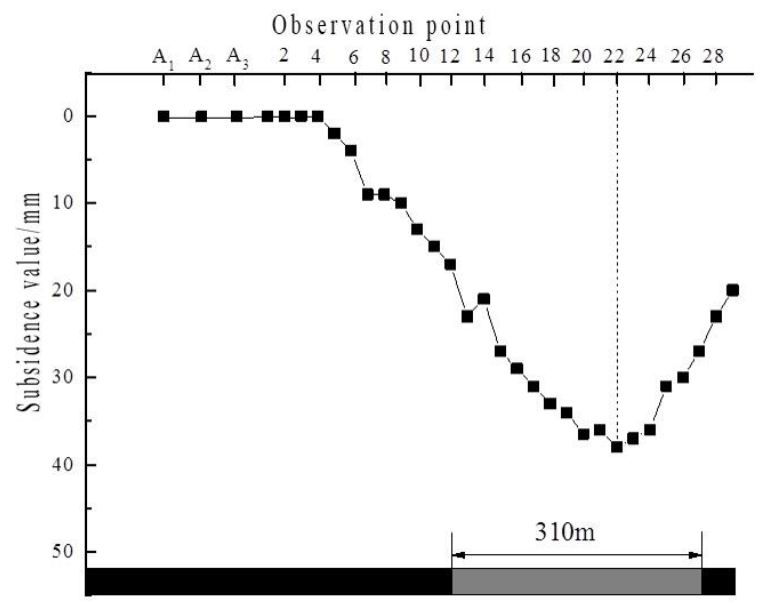

Figure 8 Relative position of surface subsidence curve and mining face

The results showed that the damage of overlying strata was slight in mining filling with paste-like Aeolian sand, and water resources under mining area can be protected.

\subsection{Production efficiency and cost}

According to the research statistics, the production capacity of single cemented backfill mining working face was 200,000 300,000 t/a, and the current filling cost of coal was 110 140 yuan per ton. By contrast, a mining filling cycle of $6.4 \mathrm{~m}$ could be fulfilled every two days. The working face was advanced by $88 \mathrm{~m}$ every month, and the production capacity of the mechanized mining filling with paste-like slurry could reach 200 300 thousand $t / a$, which was increased by nearly twice using the large capacity filling system and whole backfill space sealing; the filling cost was approximately 81.5 yuan per ton (shown in Table 6), and reduced by $35 \%$ because of optimizations such as the use of local Aeolian sand materials and simple pulping process, the installation of filling station with low energy consumption, self-gravity transportation, and less cloth consumption.

Table 3 Filling cost of Aeolian sand paste-like (per ton coal; unit: RMB)

\begin{tabular}{cccccc}
\hline $\begin{array}{c}\text { backfill material (including seal } \\
\text { cloth) cost }\end{array}$ & $\begin{array}{c}\text { depreciation fee of fixed } \\
\text { assets }\end{array}$ & $\begin{array}{c}\text { operating cost of filling } \\
\text { system }\end{array}$ & $\begin{array}{c}\text { labor } \\
\text { cost }\end{array}$ & other & total \\
\hline 55.3 & 7.3 & 1.1 & 7.0 & 10.8 & 81.5 \\
\hline
\end{tabular}




\section{Conclusions}

The backfill material uses Aeolian sand as aggregate and alkali-activated fly ash as the cementing agent. The slurry features a water-sand ratio of $1: 1.3$ and a mass concentration of $72 \%$.

The paper proposed a local resistance loss method to calculate slurry pipeline transportation. The field gravity transport test showed that resistance loss of unit length elbow was 4.26 times as great as that along the path. Hence, the pipeline diameter with 14.9 lines of self-flowing was determined, and the pipeline flow design precision was improved by over $10 \%$.

The low energy consumption arrangement mode and double pulping systems were adopted in the filling station, and the whole backfill space sealing was adopted in the working face, which improved the filling efficiency and reduced the cost.

The monitoring results of filling rate, support resistance in working face, leaching water of roof, and surface subsidence showed that the damage of overlying strata was slight in mining filling with paste-like Aeolian sand, and the overlying aquifer could be effectively protected. Meanwhile, great breakthroughs have been achieved in cost and production efficiency compared with similar technology.

In view of excellent mechanical behavior and strata movement control of paste-like Aeolian sand, the filling ratio should be optimized and the feasibility of partial filling mining should be studied so as to further improve economic efficiency and promote wider applications in the mining area in Northwest China.

\section{References}

Cui, F., Zhang, H.X. 2009, 'Feasibility Analysis of Aeolian-sand for Underground Stowing', Coal Mining Technology, vol. 14, no. 3, pp. 42-43,56.

Fan, L.M., Ma, X.D. and Ji, R.J. 2015, 'Progress in engineering practice of water-preserved coal mining in western eco-environment frangible area', Journal of China Coal Society, vol. 40, no. 8, pp. 1711-1717.

Feng, G.M., Sun, C.D., Wang, C.Z. and Zhou, Z. 2010, 'Research on goaf filling methods with super high water material', Journal of China Coal Society, vol. 35, no. 12, pp. 1963-1968.

Fu, Y., Xie, Y. and Liu, D.K. 2003, 'New technology test of self flowing filling slurry pipeline', Nonferrous Metal, vol. 55, no. 5, pp. 8-11.

Hu, B.N. 2012, 'Backfill Mining Technology and Development Tendency in China Coal Mine', Coal Science and Technology, vol. 40, no. 11 , pp. $15-18$.

Jiang, J.H. 2012, 'Study on preparation, structures and properties of mine backfill materials from mud solidification', Hunan University of Science and Technology.

Liu, J.G. and Zhao, L.T. 2014, 'Theory of water protection and practice application in mining based on the backfilling mining technology', Journal of China Coal Society, vol. 39, no. 8, pp. 1545-1551.

Lu, Y.Z. 2006, 'Study on the movement law of overlying strata under the control of coal gangue paste filling method', Central South University.

Miao, X.X. 2012, 'Progress of fully mechanized mining with solid backfilling technology', Journal of China Coal Society, vol. 37, no. 8 , pp. $1247-1255$.

Qiu, M., Shi, L.Q., Yu, X.G., Gao, W.F. and Shi, Y.K. 2016, 'On preventing the high pressure water-inrush from floor with paste-like backfill mining', Journal of Mining \& Safety Engineering, vol. 33, no. 3, pp. 409-414,422.

Sun, A.G. and Yang, Y.W. 2015, 'The practice of backfilling mining under aquifer in Wu gou Coal Mine', Energy Technology and Management, vol. 40, no. 6, pp. 105-107.

Sun, K.H. 2014, 'Experimental research on Aeolian sand paste-like stowing material for mine', Coal Technology, vol. 33, no. 5, pp. 262-265. 
Sun, K.H., Liu, P.L. and Sun, W.M. 2016, 'Research and application on Aeolian sand paste-like stowing material for mine', Metal Mine, vol. 4, pp. 172-176.

Wang, X.D. 2016, 'Relationship between engineering performance and mix proportion of fly ash for cemented and high concentration backfill material with wind blown sand as aggregate', Journal of Engineering Geology, vol. 24, no. 1, pp. 78-86.

Xia, Y.C., Du, R.J., Sun, X.Y. and Du, X.H. 2016, 'Countermeasure of ecologic phreatic water protection and mine water disaster prevention in northern Shanxi Coalfield', Coal Science \& Technology, vol. 44, no. 8, pp. 39-45.

Yan, S.H., Liu, Q.M., Zhang, H.X. and Wang, H.X. 2008, 'Backfill mining technology for gateway and pillar top coal caving mining under aquifer of shallow thin bedrock', Coal Science and Technology, vol. 36, no. 1, pp. 1-3,14.

Zhang, J.W., Ni, W., Hu, W. and Huang, X.Y. 2013, 'Research on the fluidity of backfilling material with preparation of steel slag gel system', Metal Mine, vol. 443, no. 5, pp. 153-156,168.

Zhang, J.X., Li, M., Deng, X.J. and Li, J. 2014, 'Method and application of extending mining upper limit under aquifer by gangue backfill mining', Journal of Mining \& Safety Engineering, vol. 31, no. 2, pp. 220-225. 